\title{
A CIDADE INDUSTRIAL BRASILEIRA E A POLÍtICA HABITACIONAL NA ERA VARGAS (1930-1954)
}

\section{The Brazilian Industrial City And The Housing Policies In Vargas Era (1930-1954)}

\section{Nilce Cristina Aravecchia Botas}

Departamento de História da Arquitetura e Estética do Projeto da Faculdade de Arquitetura e Urbanismo da Universidade de São Paulo nilce_aravecchia@hotmail.com

\author{
Ana Paula Koury \\ Centro de Pesquisa - Universidade São Judas Tadeu \\ apkoury@gmail.com
}

\section{Resumo}

A relação entre habitação e cidade é um dos temas mais caros à literatura que se dedicou à crítica do planejamento urbano como instrumento tecnocrático do Estado autoritário no Brasil. Originada entre as décadas de setenta e oitenta, seus autores estruturaram uma nova agenda, participativa para a política urbana brasileira e atuaram como importantes agentes de mobilização social no processo de redemocratização na década de 1980. As mais importantes conquistas recentes da política urbana brasileira são, de certo modo, tributárias desta agenda.Este trabalho pretende realizar um balanço do tema à luz do estudo da produção habitacional na era Varguista e de sua contribuição no processo de urbanização brasileiro, reconhecendo os avanços do debate nas últimas décadas bem como as "pistas falsas" deixadas por ele.

\section{Palavras chave}

história da habitação, urbanização brasileira, desenvolvimento urbano

\section{Abstract}

The relationship between housing and city is one of the most important to the literature devoted to criticism of urban planning. The main tool of the technocraticy and the authoritarian State in Brazil. Originated from the seventies and eighties, the authors that criticized the authoritarian State in Brazil have structured a new agenda for participatory urban policy. They served as important agents of social mobilization in the process of democratization in the 1980s. The recent achievements of the 
Brazilian urban policy are, in a way, related by this agenda. This work intends to conduct an evaluation of the this literature in light of the study of housing production in the Vargas era and its contribution to the process of urbanization in Brazil, recognizing the advances of the debate in recent decades and the "false clues" left by him.

\section{Keywords}

housing history, Brazilian urbanization, urban development

\section{A CIDADE INDUSTRIAL BRASILEIRA E A POLÍtICA HABITACIONAL NA ERA VARGAS (1930-1954)}

A crise do planejamento na matriz européia e norte americana permitiu desmontar a estrutura ideológica da modernidade. Alguns autores explicitaram a falsidade da pretendida ruptura histórica das vanguardas culturais, e ainda, o compromisso estabelecido principalmente após a segunda guerra mundial, entre o Estado modernizador e a dominação de classe. A crítica inaugura a pós-modernidade que, entretanto, não se mostrou menos ideológica do que a modernidade que a precedeu. Os valores da comunidade- em oposição às instituições burocráticas do estado modernizador- transformaram-se rapidamente em potentes argumentos para a desmontagem dos mecanismos institucionais de controle social que caracterizaram a modernidade, justificando o encolhimento das funções do Estado.

Dentro desta moldura teórica de crítica à modernidade, a ação do Estado Varguista na produção de habitação social embora tenha sido reconhecida como originária e difusora das utopias sociais modernas não tem sido considerada como uma política habitacional em sentido estrito (Bonduki, 1998). A dúvida é suscitada principalmente pelas análises que aprofundam o estudo da relação entre o sistema previdenciário de aposentadoria e pensões e o financiamento de unidades para os trabalhadores brasileiros que se estabelece de modo regulamentado a partir de 1937 (Cohn, 1981).

As críticas se apóiam na inexistência de uma função precípua das instituições previdenciárias para o atendimento das necessidades de moradia e da exigüidade do atendimento frente a crise habitacional que se intensifica nas principais cidades brasileiras já no início dos anos de 1940.

A ação, de fato, teria servido mais ao suporte político do populismo do que ao atendimento das classes trabalhadoras. A não universalização dos benefícios 
previdenciários provaria a natureza comprometida do Estado Varguista com o padrão de exploração do capitalismo periférico.

Formulando o problema sob outro ângulo procuraremos compreender qual foi a tarefa do Estado Varguista na modernização de uma sociedade oligárquica, agroexportadora e regida por uma democracia eivada pelo clientelismo, para então relacionar a habitação e o modelo de cidade implícito na atuação dos Institutos de Previdência desde a regulamentação das Carteiras Prediais (1937) até o concurso de Brasília (1956).

\section{Habitação e cidade na era Vargas}

Em 1920 a população urbana brasileira era $16 \%$ da população total (cerca de 5 milhões de habitantes) em atingindo 31\% em 1940 (cerca de 13 milhões de habitantes) e 36\% em 1950 (cerca de 19 milhões de habitantes). O Relatório das Nações Unidas situa o grau de urbanização. As cidades mais populosas, Londres, Paris, Berlin, Tóquio e Nova York passavam de 4 milhões de habitantes em 1920. Na América Latina as cidades mais populosas eram Buenos Aires com mais de 2 milhões de habitantes, seguida pelo Rio de Janeiro com 1 milhão e 300 mil habitantes, e depois a cidade do México e São Paulo, com 675 mil habitantes e 600 mil habitantes respectivamente.

Os países mais desenvolvidos apresentam as maiores taxas de população urbana e as menores de população rural. Entretanto uma população urbana concentrada em uma rede urbana pouco diversificada e bastante desigual em termos de sua concentração também caracteriza o subdesenvolvimento.

O Relatório das Nações Unidas (United Nation, 1969), não confirma o quadro de Araújo Filho (1958: 180) de que havia apenas 18 cidades entre 430 e 800 mil habitantes no mundo em 1920, entretanto confirma o vigor das transformações urbana que sofreram as duas maiores cidades brasileiras, São Paulo e Rio de Janeiro entre as décadas de 1920, início da modernização e expansão urbana brasileira, e 1960, quando o quadro populacional do país inverte-se, ultrapassando os $50 \%$ de população vivendo em cidades.

\section{As instituições criadas para prover moradia urbana}

A interrupção do fluxo de importações durante a primeira guerra funcionou como catalisador do processo de enraizamento da modernização social em meio urbano no Brasil. A necessidade de substituição das importações foi o elemento dinâmico para o aprofundamento das estruturas sociais urbanas. Ainda que a 
formação da agricultura exportadora brasileira tenha sido, desde a colônia, articulada a uma importante rede urbana como demonstra o estudo inaugural de Reis Filho (1968) e, ainda que, a modernização institucional durante o Império tenha fornecido importante impulso para a formação urbana do país (Singer, 1968; Azevedo, 1958), foi no fluxo das transformações mundiais da primeira guerra que o país encontrou as dificuldades que o impeliu ao ciclo urbano industrial ao qual a Era Vargas, responde, mas também em certo sentido inaugura com a revolução de 1930.

As tensões que emergem do processo de urbanização e principalmente a falta de alojamento colocam, ao Estado e à iniciativa privada os primeiros desafios e as primeiras oportunidades. As péssimas condições em que se instala a mão de obra nas grandes cidades constituem este quadro. Ao Estado cabe formular as políticas embrionárias e, principalmente, as interferências sanitárias de caráter "higienista". Tais medidas asseguram as condições mínimas para a formação de um reservatório de mão de obra urbana pronta para o regime de assalariamento necessário à industrialização. Por outro lado forma-se o mercado rentista, que explora a renda salarial através do aluguel de unidades de moradia.

Este processo clássico de formação da cidade industrial ${ }^{1}$ encontra, nas especificidades do capitalismo periférico, os defeitos que impedirão que ambos os setores, Estado e iniciativa privada, desempenhem seus papéis tradicionais no processo de formação da cidade industrial brasileira. O "setor informal", ao contrário logo encontrará um lugar na formação urbana específica do capitalismo periférico como apontado por Oliveira (1972).

Portanto não foi apenas por "omissões" dos setores clássicos, Estado e iniciativa privada, que predominou a informalidade no espaço urbano-habitacional brasileiro, investigar suas origens é uma maneira de desvencilhar-se das "pistas falsas $^{\prime 2}$ deixadas pelas suas explicações.

Brito (1985) descreve as primeiras ações públicas logo no primeiro período republicano (1889-1930); o decreto 4.029 de 1920 no qual "(...) o governo Epitácio Pessoa dá início no país a política oficial de construção de casas para o aluguel (...)". O decreto autoriza expressamente a ação direta do poder público no setor da moradia para os trabalhadores. No ano seguinte o decreto 14.813 regulamenta a ação de terceiros e ainda o decreto 15.068 institui a Sociedade Anônima "A Popular" beneficiando-a com os incentivos autorizados pelos decretos anteriores.

\footnotetext{
${ }^{1} \mathrm{O}$ processo foi descrito inicialmente por Engels (1887) em seu estudo sobre as condições de alojamento da classe operária na Inglaterra, dando elementos para toda a bibliografia sobre cidade industrial.

${ }^{2}$ Refere-se à revisão da herança institucional Varguista proposta por Santos (2006).
} 
Regulamentando, deste modo, as funções dos setores tradicionais na produção de moradia urbana.

As primeiras instituições com a função de dar assistência previdenciária aos trabalhadores são as Caixas de Aposentadoria e Pensões criadas para cada uma das empresas ferroviárias em 1923. O Decreto 4.682 do governo de Arthur Bernardes, também conhecido por Lei Eloi Chaves, é considerado um marco legislativo da previdência social brasileira e garantiu um conjunto de direitos sociais aos trabalhadores, nos quais se incluía a construção de unidades habitacionais. Na sequência das caixas para as empresas do setor ferroviário, em 1926 o regime foi estendido para os portuários e marítimos, em 1928 para os trabalhadores dos serviços telegráficos e radiotelegráficos e, em 1930 para os serviços de força, luz e bondes.

A criação do Ministério do Trabalho, Indústria e Comércio em 1930 significou uma importante modificação no controle dos recursos da Previdência Social. Além da criação dos Institutos de Aposentadoria e Pensões por setor funcional, ao contrário do que eram as caixas, organizadas por empresas, o Estado passou a controlar estes fundos que se tornariam importantes para financiar não apenas a previdência dos trabalhadores mas também os projetos de infra estrutura para o desenvolvimento industrial do país.

Os Institutos assim como as Caixas tinham o objetivo de assegurar aposentadoria e pensões para os seus beneficiários e secundariamente assistência médica e a oferta de moradia através da construção de conjuntos habitacionais. A produção de moradia pelos institutos de previdência social foi regulamentada em 1937 por meio das Carteiras Prediais, permitindo várias modalidades de investimentos no setor habitacional (Cohn, 1981; Bonduki, 1998). Esta iniciativa foi a origem da promoção pública no setor de moradias econômicas no país.

Também no final da década de 1930, com o objetivo de incrementar a produção de moradia urbana e conter os assentamentos urbanos informais foram criados dois importantes órgãos regionais em duas das três maiores concentrações urbanas brasileiras, no Rio de Janeiro e em Recife. Em Recife a Liga de Combate Contra os Mocambos criada em 1939 chegou a produzir cerca de 1.500 unidades e, na década de 1940, o Serviço dos Parques Proletários no Rio de Janeiro chegou a produzir cerca de 1.100 unidades.

Apenas em 1946 com a Fundação da Casa Popular, que foi criado um órgão federal com fundos unificados e com o único objetivo de produzir moradia urbana e rural para os trabalhadores brasileiros. Seu projeto original previa a reunião dos recursos dispersos nos institutos previdenciários criando, assim, as condições 
desejáveis para empreender uma política universal fazendo frente à expansão da crise de moradia em meados de 1940. (Manoel, 2004).

\section{A produção dos institutos previdenciários e da Fundação da Casa Popular}

Entre 1940 e 1950 cerca de seis milhões de pessoas foram urbanizadas no Brasil $^{3}$. No mesmo período a superlotação cresceu 2,3 milhões, estimada em 9,3 milhões de pessoas em 1940 atingiu 11,6 milhões de pessoas em 1950. A carência de unidades habitacionais no país aumentou em 400 mil unidades entre 1940 e 1950. De 1,5 milhões para 1,9 milhões. ${ }^{4}$

As inversões federais no setor habitacional até 1964 alcançou 142.127 unidades (Bonduki, 1998:129). Resultado da ação conjunta da Fundação da Casa Popular, criada em 1946 e dos institutos de previdência, reunidos em 1930 por categorias profissionais. Este número de unidades incluía desde conjuntos construídos para locação, destinados aos trabalhadores de menor renda, até os vultosos investimentos no setor imobiliário que tinham como objetivo garantir a rentabilidade dos fundos previdenciários.

Deste montante a produção da Fundação da Casa Popular atingiu a modesta cifra de 17.832 unidades. A maior parte delas, 7.230 unidades produzidas no período do governo de Dutra (1946-1950), 4.381 durante o segundo governo Vargas (19511954) e 6.221 construídas em Brasília durante o governo de Kubitscheck (19551960), e nenhuma unidade construída depois disso. (Manoel, 2004:75). Por outro, os institutos de previdência produziram até 1964 cerca de 31.000 unidades apenas considerando as unidades para a locação, destinadas aos trabalhadores com menor rendimento.

A tabela abaixo demonstra a produção de unidades por período político no Brasil, comparando a quantidade produzida pelos Institutos de Aposentadoria e Pensões e pela Fundação da Casa Popular. Os números evidenciam a dificuldade de operação da Fundação.

\footnotetext{
3 Dados calculados pela autora a partir dos censos demográficos do IBGE -Séries Históricas acessados em 2011. A população total do país em 1940 era 41.236 .315 cerca de 10 milhões estavam vivendo em cidades, em 1950 este número cresce para cerca de 16 milhões em um total de 51.944.397 de habitantes no país.

4 Dados apresentados por Almeida na carta de encaminhamento do relatório da Subcomissão de Habitação e Favelas. CPDOC Arquivo: Getúlio Vargas Classificação: GV c 1952.12.23. Data:23/12/1953. Para efeito de cálculo o autor considerou 2 habitantes por quarto em unidades de 3 quartos.
} 
Tabela 1- produção de unidades por período político no Brasil, comparando a quantidade produzida pelos Institutos de Aposentadoria e Pensões e pela Fundação da Casa Popular.

Fonte: MANOEL, S. K. (2004). Fundação da Casa Popular: projeto frustrado de construção de uma política habitacional no Brasil. São Carlos: Dissertação de mestrado. EESC - USP.

\begin{tabular}{|c|c|c|c|c|c|}
\hline & & & & \\
\hline & & & & \\
\hline & DUTRA & VARGAS & JK & JANGO & TOTAL \\
\hline & $1946-1950$ & $1951-1954$ & $1955-1960$ & $1961-1964$ & $1946-1964$ \\
\hline FCP & 7.230 & 4.381 & 6.221 & ZERO & 17.832 \\
\hline IAPs (planoA) & & & & & 31.099 \\
\hline
\end{tabular}

MANOEL, Sálua Kairuz, Fundação da Casa Popular: projeto frustrado de construção de uma política habitacional no Brasil. São Carlos: Dissertação de mestrado. Escola de Engenharia de São Carlos. Departamento de Arquitetura e Urbanismo- USP, 2004. p. 75

Entre 1940 e 1950 a população das duas maiores capitais do Brasil, São Paulo e Rio de Janeiro, cresceram cerca de 1,5 milhões de pessoas, concentrando $25 \%$ do crescimento da população total do país no período. São Paulo passa de 1,3 milhões para 2,2 milhões de habitantes, e o Rio de Janeiro passa de 1,7 para 2,3 milhões.

Do montante total das 142.127 unidades produzidas pela ação federal no período até 1964, 51.684 concentraram-se no estado do Rio de Janeiro, e 28.387 em São Paulo. Portanto mais de $50 \%$ do total concentrou-se nos estados de São Paulo e Rio de Janeiro. Considerando que depois de 1956 grande parte dos recursos dos fundos previdenciários foram drenados para a construção da nova capital, o impacto destas cifras na produção das cidades de São Paulo e Rio de Janeiro entre as décadas de 1940 e 1950 são ainda mais impactantes.

O gráfico abaixo demonstra a concentração de unidades produzidas pelos Institutos de Aposentadoria e Pensões na cidade do Rio de Janeiro. O fato é mais evidente se considerarmos que a cidade do Rio de Janeiro recebeu quase a totalidade das unidades produzidas no Estado. O que não ocorreu nos demais estados. A cidade de São Paulo, por exemplo, recebeu cerca de metade da produção estadual de unidades. 
Gráfico 1

Fonte: Tabulação de dados da pesquisa Pioneiros da Habitação Social no Brasil

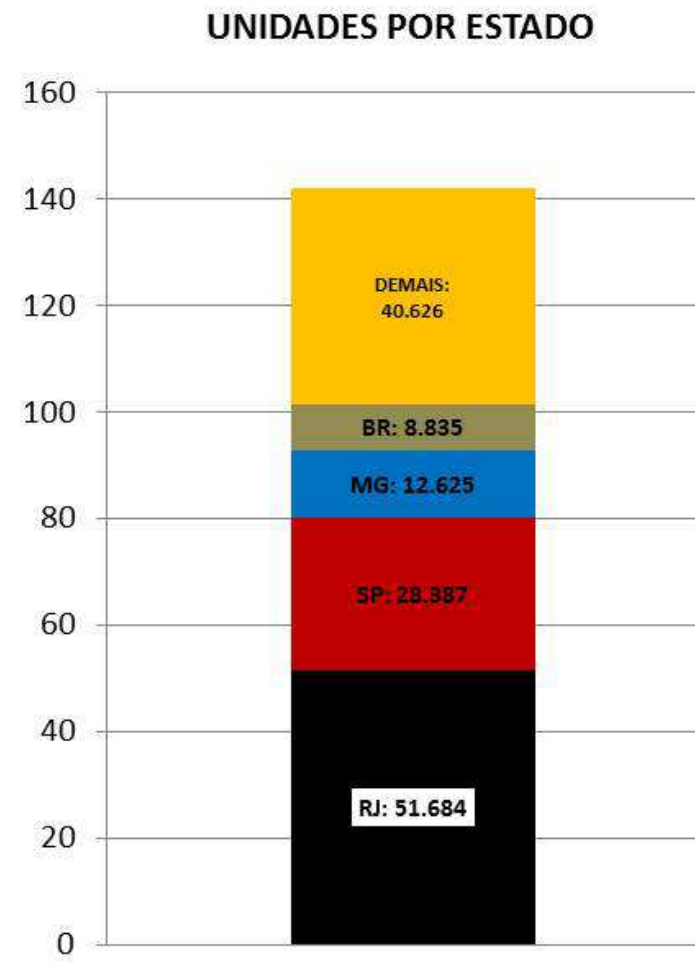

A produção habitacional dos institutos previdenciários e da Fundação esteve longe de atender a necessidade de moradia decorrente do processo de urbanização da sociedade industrial no Brasil e ainda mais longe de atender à necessidade de habitação das classes de menor renda. Os indicadores do atendimento aos associados dos institutos mostram que, exceto a categoria dos bancários - o que concentrou os maiores fundos de todos os institutos, atingiu uma taxa de atendimento de cerca de $30 \%-$, os demais tiveram taxas de atendimento muito inferiores, ficando abaixo dos 5\% dos trabalhadores associados. Entretanto, considerando a concentração do atendimento nas cidades com mais de 50 mil habitantes, a produção dos institutos alcançou $10 \%$ da população, onde o problema habitacional se concentrava. Taxa ainda mais elevada na cidade do Rio de Janeiro, onde os institutos atenderam $25 \%$ 
das necessidades de moradia e contribuíram significativamente para o incremento do mercado imobiliário da cidade (Bonduki, 1998: 128-131).

\section{A ação do Estado Varguista na estruturação das cidades do Rio de Janeiro e de São Paulo}

Até o início do século XX, a maior concentração da produção industrial estava no Rio de Janeiro que, ao longo da década de 1920 perde o posto para São Paulo ${ }^{5}$. O processo que garantiu a primazia econômica à capital paulista, localizada na mesma região geoeconômica da capital do país é explicado por Paul Singer (1968) através do acesso aos mercados. Pela sua posição geográfica São Paulo teve acesso privilegiado à área "onde se encontrava a maior parte do mercado interno brasileiro". Estas ligações foram em certa medida reforçadas pela malha ferroviária que dividiu os principais mercados do país em duas grandes regiões: uma conectada ao Rio e formada, além do próprio estado do Rio de Janeiro, pela Zona da Mata Mineira, Espírito Santo e Bahia; e outra conectada a São Paulo, e formada pelo interior desse estado, Sul de Minas, Triângulo Mineiro, Paraná, Santa Catarina e Rio Grande do Sul. Região que com maior intensidade ainda no final do século XIX substituiu a sua economia de subsistência pela exportadora, processo impulsionado pela economia cafeeira que mobilizou o trabalho assalariado, integrou o território pelas ferrovias, e impulsionou a economia urbana e o fluxo de capitais. Tal dinâmica permitiu ao sistema São Paulo - Santos, inaugurado no final de 1860, a concentrar, no início do século $X X$, o desenvolvimento regional do país, e a se constituir como centro dinâmico da economia nacional. (Singer, 1968: 28-66).

Ao mesmo tempo as alterações ocorridas na estrutura dos custos da indústria carioca, resultantes de gastos com transporte, energia e salários, responderam pela menor competitividade de seus $\operatorname{produtos}^{6}$ (Freitas Fo., 2002).

O processo de urbanização acelerado toma proporções e características distintas em cada capital. No intervalo de 1920-40 cerca de 170 mil trabalhadores são empregados na indústria paulistana. Mas, ainda que o Rio de Janeiro tenha perdido posição em relação a São Paulo, não fica à margem da industrialização e mais de cem

\footnotetext{
${ }^{5}$ Entre 1920 e 1938 o crescimento industrial paulista supera o carioca. Singer, 1968:49.

6 Freitas Fo. (2002) compara as interpretações tradicionais que tratam do processo de concentração industrial em São Paulo como resultado da organização do "complexo cafeeiro" e a introdução do trabalho assalariado, com outras abordagens que analisam a organização espacial e custo de vida como outros informantes deste processo. Para esta análise: Cano, 1981; Pignaton, 1977; Guarita, 1986 ; Levy, 1994.
} 
mil trabalhadores também são empregados em fábricas na cidade, no mesmo período ${ }^{7}$.

A economia carioca acaba por se diversificar em amplos setores, principalmente no comércio, nos serviços e, no que diz respeito à industrialização, será grande o incremento no setor da construção civil. As reformas, que iniciadas por Passos continuam nas administrações seguintes, tornam o Rio a grande vitrina para entrada no país, que recebe neste momento o título de cidade maravilhosa.

Após os anos da Grande Depressão tornou-se cada vez maior o movimento do capital imobiliário na cidade. Com receio de fazer investimentos no setor financeiro, muitos investidores optaram pela construção de imóveis nas áreas mais valorizadas da cidade. Tal movimento foi acompanhado do grande contingente migratório que chegava ao Rio em busca de trabalho na construção civil, gerando, conseqüentemente, nova demanda por habitação. A corrida imobiliária tomou tal dimensão que acabou por propiciar sérias distorções na economia urbana, drenando capitais que poderiam ter ido para indústria, exagerando na demanda pela mão de obra na cidade, e dirigindo investimentos em habitações de alta renda, numa época em que migrantes pobres assoberbavam o mercado de moradias de baixa renda (Conniff, 2006:129-30). Essa canalização dos investimentos não passou sem críticas pelos que defendiam a industrialização, que acusavam de falta de patriotismo a prática especulativa, como fica explícito na fala de Assis Chateaubriand (1939)

Mas o Rio de Janeiro que é que tem, para justificar tanto dinheiro aplicado em edifícios suntuosos? Sua indústria, como força real, muito pouco ainda significa. Quanto ao poder agrário do seu hinterland, não é preciso mais do que tomar o Estado do Rio dessorado, e Minas com uma economia quase primitiva, incapaz de oferecer alicerces mesmo para uma medíocre metrópole de arranha-céus.Logo o dinheiro que vem para o Rio em busca de emprego em residências, procura um centro de dissipação, economicamente pobre, e artificialmente rico, porque aqui se despende, sobretudo, é uma grande parte do orçamento federal.Somos de preferência uma cidade de funcionários públicos, em vez de um centro de indústrias organizadas, com um interior produzindo para estabelecer o equilíbrio de trocas entre o campo e o aglomerado urbano. Conheço dezenas de homens ricos que arrebatam economias indispensáveis as suas indústrias locais, ao desenvolvimento dos seus campos, para edificar sobrados de dez andares no Rio.Esses desalmados

\footnotetext{
7 Recenseamentos, Distrito Federal, 1920 e 1940, dados para o Rio de Janeiro compilados por Connif, 2006:231 e para São Paulo por Silva, 1983:29.

8 O excerto do artigo de Assis Chateubriand, intitulado "Contra o urbanismo artificial", foi retirado da Revista do IAPC de janeiro de 1939, o que demonstra o encontro entre os interesses do Estado e os dos adeptos do desenvolvimento industrial, mesmo daqueles que eram opositores políticos, caso de Chateubriand.
} 
deveriam ser perseguidos pelo poder público dos seus estados, como inimigos do Brasil (Chateaubriand, 1939)

Mas a expansão física da cidade, que como se pode perceber, também foi impulsionada pela dinâmica imobiliária, que afetou positivamente diversos ramos da indústria local. A função de Capital da República, e de importante centro cultural, estimulou o ramo editorial e gráfico e o próprio destaque da construção alimentou o desenvolvimento de atividades correlatas - como a metalurgia, as indústrias mecânicas e elétricas, a produção de telhas, tijolos, tubos, aparelhos sanitários, cimento - que tinham em vista atender à demanda de novas moradias. (Freitas Fo., 2002).

A cidade de São Paulo também crescia integrada à expansão dos meios de transporte que a tornaram o importante centro regional. Imigrantes e migrantes de outras regiões ou da zona rural eram atraídos pelo desenvolvimento econômico pressionando as fronteiras da cidade. Entre 1920 e 1940 São Paulo recebeu 758.611 novos habitantes em uma população de 579.033 habitantes em 1920. Enquanto o Rio de Janeiro recebeu 623.694 novos habitantes em uma população de 1.157 .873 habitantes, no mesmo período.

A valorização imobiliária, no início da década de 1930 atingiu os diversos bairros paulistanos de modo intenso e em diferentes circunstâncias. Enquanto os bairros mais valorizados, como Higienópolis e Av. Paulista, foram sendo verticalizados e as mansões e casarios das classes ricas deslocavam-se para o Pacaembu, Jardim América e Sumaré, novos loteamentos periféricos iam sendo abertos ao longo dos principais eixos de ligação, as linhas ferroviárias, as linhas de bonde e posteriormente as grandes avenidas do Plano de Avenidas de Prestes Maia. A cidade expandiu-se majoritariamente para Leste, Sudeste e Sul. Para leste ao longo da Central do Brasil os bairros do Brás e da Penha abrigaram a maior expansão de bairros operários. Estes bairros também ocuparam, na direção sudeste, ao longo da ferrovia, "preparando a marcha no rumo de São Caetano e Santo André". (Petrone, 1958: 149). Ao sul a linha de bondes, a ligação rodoviária e a construção das represas da Light consolidaram a ligação da cidade com o núcleo de Santo Amaro, constituindo uma ocupação de classe média e também de algumas indústrias.

A industrialização paulista no primeiro quartel do século $X X$ era majoritariamente concentrada nos bairros da zona leste, Brás, Mooca e Belenzinho e era composta por indústrias de alimentação e têxteis seguidas pelas metalúrgicas e mecânicas, químicas e farmacêuticas, cerâmica, vidros e cristais, construção civil, 
vestuário, materiais de transporte (construção e montagem), borracha e papel. (Matos, 1958: 41-42).

A habitação passou a ser condição básica de reprodução da força de trabalho na cidade, e a diminuição de seu custo ao trabalhador representava também a diminuição dos salários ao seu empregador. Ao longo da década de 1920, o problema da moradia dos trabalhadores deixou de ser tratado como empecilho às reformas dos melhoramentos urbanos nas áreas centrais e foi admitido como parte da transformação das cidades. A mobilização dos setores populares urbanos na revolução de 1930 expunha o potencial político que a questão social urbana, incluindo a habitação, ganharia durante o Varguismo.

As reivindicações por melhores condições de vida na cidade do Rio de Janeiro tornaram-se cada vez mais combativas. Na dinâmica política contava, por um lado a aproximação às massas urbanas conformando o populismo como base de sustentação do autoritarismo do Estado Novo, e por outro ampliando os fatores sociais estratégicos à industrialização do país.

No Rio de Janeiro, nessa lógica modificou-se a visão em relação aos subúrbios, o que resultou em melhorias para estes bairros mais distantes, e também no investimento por parte do Estado em áreas nitidamente industriais (Abreu, 2006:95).

Em São Paulo, a expansão da mancha urbana, sua verticalização e o seu desenvolvimento periférico caracterizam a forma da urbanização promovida pelo dinamismo econômico da capital do estado. Os bairros populosos e distantes do centro que caracterizavam a ocupação nuclear rarefeita da cidade no século XIX deu lugar a uma ocupação contínua, que preencheu os vazios entre eles e ampliou o centro da cidade. Em um processo análogo, a ocupação também expandiu-se perifericamente até encontrar os municípios de Santo André e São Caetano na década de 1950 e posteriormente São Bernardo, iniciando a conurbação que caracteriza o território metropolitano desde então.

As ações do Estado no campo da moradia das classes de menor renda dariam grande visibilidade ao programa de amparo ao trabalhador, assento político do Varguismo. As inaugurações dos primeiros conjuntos operários em São Paulo, produzidos pelos institutos de previdência ainda durante o Estado Novo, produziram grande impacto. Estes conjuntos de grande porte inovaram por suas formas arquitetônicas modernas e pelo caráter exemplar da intervenção que incluía equipamentos de lazer, comércio local, creche, e serviços assistenciais. Localizados em pontos de grande visibilidade como nos bairros industriais da Mooca, e na 
Várzea do Carmo, e seguindo as avenidas de Prestes Maia, no Centro da cidade e no vetor sul, estes conjuntos, junto à lei do inquilinato que congelou os aluguéis ${ }^{9}$ no começo dos anos 1940, funcionaram como fatos políticos de grande repercussão positiva na base de apoio do trabalhismo Varguista.

No Rio de Janeiro os serviços urbanos básicos, esperados há mais de uma década eram finalmente atacados pelo poder público conquistando o apoio de bairros proletários, que eram estratégicos para a orientação política do Estado Novo. Os melhoramentos realizados nos subúrbios passam a ser anunciados sistematicamente nos periódicos:

O presidente Getulio Vargas decretou a abertura de avultado crédito para obras nos subúrbios desta capital, segundo o plano organizado pelas autoridades municipais e já recomendado pelo chefe da Nação. O fato encerra a autêntica e vigorosa expressão de um governo feito para o povo, não para angariar clientela eleitural ou popularidade fácil (OS SUBÚRBIOS [...], NOV., 1943:4 $)^{10}$.

A visita do prefeito deve começar pelo bairro Maria da Graça, que, possuindo elevado número de casas comerciais e de residências com uma população de mais de sete mil almas, permanece há longos anos esquecido dos poderes públicos. Nem se lembraram de calçar-Ihes as ruas (A VEZ [...], DEZ., 1943:4) $)^{11}$.

Paralela e constantemente, a inauguração de casas nos subúrbios para operários ocupará os noticiários:

O Sr. Prefeito Henrique Dodsworth em companhia dos Secretários de Viação e de Saúde e Assistência, fez uma série de visitas de inspeção a diversos subúrbios do Distrito Federa.

Na Penha foi oferecida à Prefeitura pelos moradores locais, uma grande área destinada a construção de uma escola que terá o nome de "Prefeito Henrique Dodsworth" por imposição dos ofertantes.

Dirigindo-se para Bangú, teve S. Ex. a satisfação de inaugurar e conceder o "habite-se a 200 casas proletárias, laçando a mesmo tempo a pedra fundamental de ouras 200.

Essas visitas têm um cunho bem expressivo por demonstrar o empenho que tem o Prefeito Henrique Dodsworth em proporcionar conforto à classe proletária que bem merece a assistência dos poderes públicos. (INAUGURAÇÃO [...], AGO., 1942: $4^{12}$ ).

\footnotetext{
${ }^{9}$ Nos valores vigentes em 31 de dezembro de 1941.

10 Notícia transcrita do jornal $A$ noite, no boletim $O$ Construtor, em 26 de novembro de 1943, p. 4.

${ }^{11}$ Nota extraída do jornal Correio da Manhã, reproduzida no boletim O Construtor, de dezembro de 1943 , pag.4.

${ }_{12}$ Notícia transcrita do Jornal do Comércio, no boletim O Construtor em 21 de agosto de 1942 , p. 4.
} 
A orientação do regime em aproximar-se das causas proletárias e o seu compromisso com a industrialização envolveram investimentos significativos nos bairros mais afastados que tornam-se foco importante da ação do Governo de Vargas no Distrito Federal. As obras na cidade foram facilitadas pela aproximação da administração de Henrique Dodsworth na prefeitura, que se inicia em 1937, com o poder central (Rezende, 2002:262).

Entre os programas iniciais do Ministério do Trabalho estava completar um projeto de moradias de aluguel subsidiado pelo governo nos subúrbios do Rio de Janeiro. O objetivo indireto era gerar alternativas de trabalho para o contingente desempregado (Conniff, 2006, p.126) ${ }^{13} .0$ projeto não foi realizado, mas os estudos dos técnicos do Ministério informaram as soluções elaboradas pelos institutos de previdência a partir da década de 1940.

A ocupação do território estava diretamente relacionada à estratégia de acomodar os interesses fabris. A maior parte dos conjuntos habitacionais foi implantada próximo às fábricas e, com eles, a Estrada de Ferro Central do Brasil que ligava São Paulo ao Rio de Janeiro demarcará um eixo fundamental de urbanização no quadro das estratégias governamentais. Se no Rio de Janeiro essa ocupação nas áreas de subúrbio consolida-se com a ajuda da implantação dos conjuntos dos institutos de previdência, sobretudo do IAPI (Instituto de Aposentadoria e Pensões dos Industriários), na cidade de São Paulo, são implantados os primeiros loteamentos de distritos como Guaianases e Ermelino Matarazo pela iniciativa privada. Mas a implantação de conjuntos do IAPI em cidades como Lorena, Guaratinguetá, Taubaté e São José dos Campos, localizados no interior do estado de São Paulo, no eixo da Central do Brasil, seguem a mesma lógica de ocupação dos territórios integrados pelo sistema ferroviário, pontuando uma rede de cidades que mais tarde receberia novos impulsos do Estado para a sua especialização dentro do sistema regional da industrialização paulista.

A produção de habitações por iniciativa pública, que acontecia de forma esparsa e assistencial, terá incremento significativo na década de 1940, por ação dos institutos de previdência dentro do planejamento político da industrialização brasileira. Com a implantação de conjuntos habitacionais promovidos por esses órgãos

\footnotetext{
${ }^{13} \mathrm{~A}$ Informações foram reunidas por Michael Conniff, a partir de páginas do Jornal do Brasil de dezembro de 1930. CONNIFF, 2006:126.
} 
chegavam uma série de outras melhorias que acabavam por atrair novos contingentes populacionais e o desenvolvimento urbano para as áreas de subúrbio.

Os institutos de previdência, no desenvolvimento de suas atividades atuariais, entram na engrenagem do processo de urbanização de forma bastante contraditória. As formas de ocupação do território incluem a dinâmica do mercado imobiliário, isto é, os agentes e as relações estabelecidas no parcelamento da terra e na produção da moradia propriamente dita (Ribeiro, 1985:5-31). Na dinâmica do crescimento da cidade e do desenvolvimento industrial surge a figura do incorporador que interfere na forma de organização da indústria da construção, e passa a controlar as diversas fases do processo de produção das moradias, desde a compra do terreno até a comercialização (Freitas Fo., 2002). Os institutos de previdência assumem o papel de incorporadores, já que em grande parte dos conjuntos habitacionais produzidos nos subúrbios, gerenciam todas as fases da produção da moradia.

Com o oferecimento de residências a aluguéis baixos aos moradores dos bairros próximos às áreas industriais o Estado atinge seus objetivos, tanto de fomentar o desenvolvimento industrial, inclusive incrementando a indústria da construção civil, quanto de arregimentar uma base política de sustentação do regime ao atender as massas de trabalhadores urbanos. Esse processo alimentou uma vertente empresarial no interior dos institutos de previdência, para a qual importava menos o impulso à industrialização e o bem-estar dos trabalhadores do que a capitalização do setor imobiliário proveniente das inversões realizadas. 0 foco era a estabilidade econômico-financeira das instituições e havia a tendência em buscar a segurança oferecida pelos investimentos imobiliários. Assim, os institutos não só possibilitaram o intenso processo de verticalização e especulação imobiliária no centro do Rio de Janeiro e de São Paulo (e de forma proporcional em outras capitais e cidades do interior do país), como foram agentes diretos desse processo tornando-se os maiores detentores individuais de terra urbana no país (Varon, 1988 e Melo, 1992 citados por Bonduki, 1998:105).

No entanto, a implantação dos conjuntos habitacionais, assim como a eletrificação da malha ferroviária, concorreu de maneira significativa para a transformação dos subúrbios cariocas e paulistas, nos anos de 1940 e 1950. A presença do Estado, que implantava também os equipamentos de serviço público, levou um aspecto de urbanidade para os bairros que tinham se originado das freguesias rurais e eram até então, habitados em condições de precariedade extrema. Certamente estas melhorias eram insuficientes, ainda mais se comparados aos bairros 
centrais que serviram de moradia às classes ricas, originalmente ligados aos equipamentos públicos e serviços urbanos de melhor qualidade.

Mas a aproximação na análise de certas localidades torna inegável a participação direta do Estado na produção dos bairros dos trabalhadores urbanos no período em questão. A população das zonas suburbanas do Rio de Janeiro teve um incremento de cerca de 380mil moradores na década de 1940 (Censos Demográficos de 1940 e 1950 citados por Abreu, 2006:109). Os institutos de previdência construíram cerca de $20 \mathrm{mil}$ unidades habitacionais nestas áreas durante este período, podendo-se afirmar que foram responsáveis por cerca de $20 \%$ da ocupação desses territórios. A circunscrição censitária do Realengo, por exemplo, tinha 95 mil habitantes em 1940 e passa para 150 mil em 1950. Deste acréscimo de 65 mil pessoas, considerando o número médio de pessoas por família, que era de 4 , só o Conjunto Residencial do Realengo, com 2.344 unidades construídas pelo IAPI durante a década de 1940, correspondeu a $15 \%$ do aumento da população do local, sem considerar outros conjuntos habitacionais e empreendimentos que foram construídos naquela região.

A imagem abaixo demonstra a grande variedade tipológica do Conjunto Residencial do Realengo, bem como a sua grande dimensão. A foto tirada por cima em data próxima à inauguração do conjunto foi levantada junto aos antigos moradores, ativos na defesa da memória e do significado desta produção habitacional.

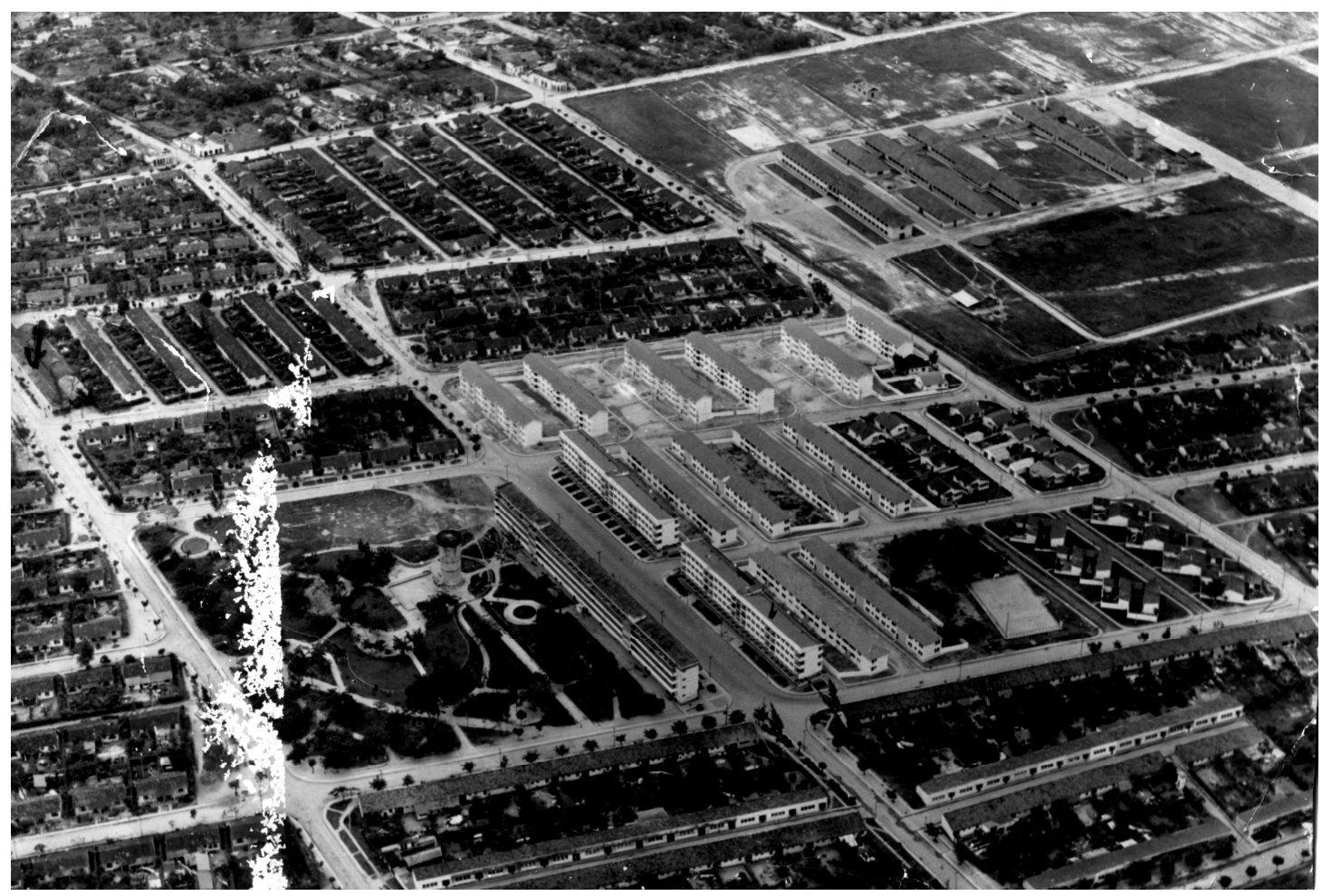


Figura 1: Foto aérea do conjunto de Realengo no Rio de Janeiro anos 1940. Levantamento realizado junto aos moradores sem identificação de autoria.

Fonte: Acervo da pesquisa Pioneiros da Habitação Social no Brasil coordenada por Nabil Bonduki.

Pode-se afirmar que a ação estatal respondeu pela feição tomada pelos subúrbios cariocas a partir dos anos de 1940, mas, agindo de forma contraditória, não conseguiu direcionar todo o processo de ocupação urbana e acabou por impulsionar a lógica especulativa. Mas entre os técnicos da previdência, responsáveis pela produção habitacional, havia a preocupação de pautar-se em uma iniciativa planejada. (Botas, 2011).

Em São Paulo embora a população suburbana também tenha aumentado consideravelmente a construção de conjuntos dos institutos de previdência nestas áreas não foi tão significativa como no Rio de Janeiro.

A produção privada que até a lei do inquilinato encontrava na moradia uma inversão rentável encarregou-se, em certa medida, da oferta para as classes médias e para os trabalhadores urbanos. Foi a produção de unidades na rede urbana do interior do estado e dos municípios conurbados como Santo André ou próximos à área metropolitana como Suzano que de fato produziu um impacto urbanizador próximo àquele verificado nos subúrbios cariocas.

O Conjunto Residencial Vila Guiomar é um caso exemplar, com cerca de 1.400 unidades residenciais construídas - o projeto original contava com mais de 3.000 unidades - significou, com seus 5.600 moradores estimados, 6,2\% do incremento populacional do município na década de 1940, quando a cidade já contava com uma população de 89874 habitantes ${ }^{14}$. Santo André caracterizou-se como o mais importante subúrbio industrial da capital paulista no entre guerras e em 1943 já era "um dos mais importantes parques industriais do continente sul-americano." ${ }^{15}$ Osasco também caracterizou-se neste mesmo período como importante subdistrito industrial à oeste da capital paulista, e recebeu um conjunto com 357 unidades - de um projeto que previa a construção de 3 mil. As unidades embora insignificantes frente ao projeto original demonstram uma clara intenção de realizar conjuntos de impacto nas zonas industriais dos subúrbios em expansão.

\footnotetext{
${ }^{14}$ Se essa comparação for apenas sobre a população urbana de Santo André o impacto é certamente maior. Situação demográfica, estado da população do Brasil na data do recenseamento geral de 1940 . IBGE www.ibge.com.br. Acesso em 18/04/2013.

15 AZEVEDO, Aroldo. Subúrbios de São Paulo (Primeiros estudos) Anuário da Faculdade de Filosofia do Instituto "Sedes Sapientiae". São Paulo:1943,citado porPENTEADO, 1958:7.
} 
Abaixo a vista aérea do Conjunto de Vila Guiomar demonstra a extensão e o impacto do Conjunto. Uma boa parte do acervo iconográfico deste conjunto encontrase no Museu da Cidade de Santo André.

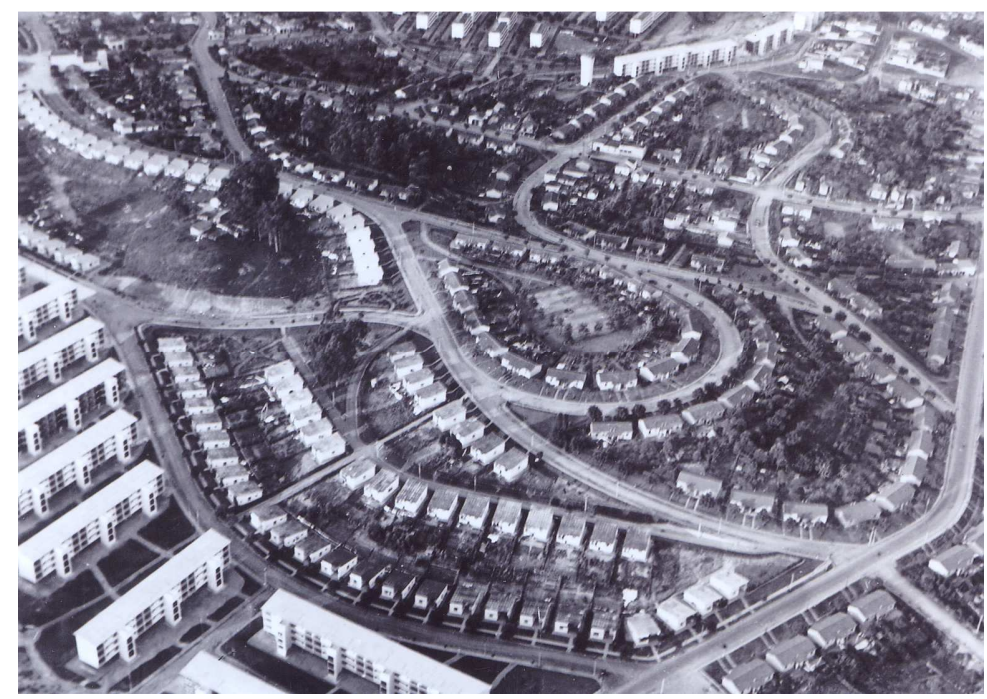

Figura 2: Foto aérea do conjunto de Vila Guiomar em Santo André anos 1950. O levantamento foi feito pela pesquisa Pioneiros da Habitação Social no Brasil coordenada por Nabil Bonduki.

Fonte: Museu de Santo André Dr. Octaviano Armando Gaiarça.

Em São Paulo, como mencionado anteriormente, a produção de unidades habitacionais pelos Institutos de Previdência não se concentrou na capital, que foi equivalente nos municípios da região metropolitana e do interior. No Rio de Janeiro ocorreu o contrário, isto é foi quase nula a produção de unidades fora da capital, e o número de unidades construídas durante o período de funcionamento dos institutos, isto é até meados da década de 1960, foi duas vezes maior do que em São Paulo $^{16}$.Mas, ainda que a produção tenha se concentrado no Rio de Janeiro, a ação estatal também contribuiu para a feição dos subúrbios metropolitanos de São Paulo a partir dos anos de 1940.

As próprias contradições que impregnaram 0 processo político comprometeram uma condução planejada mais efetiva por parte do poder público na expansão do território urbanizado, mas é importante destacar que havia essa preocupação em parte do setor técnico previdenciário.

No Rio de Janeiro dos anos 40 eram inflamados os debates acadêmicos sobre a modernidade, constituindo-se a cidade em campo de experimentação para as

\footnotetext{
${ }^{16}$ No estado de São Paulo o total de unidades produzidas pelos institutos foi cerca de 13.800 e no interior do estado 6.800. No Rio de Janeiro o total foi de cerca de 30.000 unidades excluindo os órgãos regionais e destas apenas 700 localizadas fora da cidade do Rio de Janeiro (Niteroi, Petrópolis, Nova Iguaçu e São João do Meriti). Dados da pesquisa Pioneiros da Habitação Social no Brasil Coordenação Nabil Bonduki (FAU, IAU, USP - 1999-2012).
} 
diversas correntes arquitetônicas e urbanísticas. Basta destacar que entre 1920 e 1940 realizam-se obras de envergadura que definem muito do perfil que a capital carioca carrega até hoje, como a derrubada do Morro do Castelo e abertura da Esplanada, das Avenidas Presidente Vargas e Brasil, dos túneis do Pasmado e Santa Bárbara, a criação dos bairros Urca e Leblon. Dentre essas obras, as que ampliam e constituem um sistema viário de caráter estrutural foram fundamentais para a expansão urbana que direcionou a ocupação das zonas norte e oeste da cidade. A produção habitacional pública no subúrbio foi parte fundamental desta expansão. A julgar pela padronização, pela idéia de habitação no parque, pela presença dos equipamentos coletivos, os empreendimentos são modelares do que se poderia esperar como resultado do conceito de melhor moradia pelo menor custo. Os técnicos do Estado tinham domínio do significado de seu trabalho e procuravam potencializá-lo diante das transformações pelas quais passava o país, em que pese todas as contradições políticas, sociais e econômicas. A expansão ordenada da cidade era então uma realidade e uma atribuição que lhes cabia. Os conjuntos dos institutos previdenciários, além dos realizados por outros órgãos públicos que produziram habitação no período, foram parte fundamental desta expansão, e acabaram por direcionar vários pontos de ocupação urbana no subúrbio carioca.

No caso de São Paulo o Plano de Avenidas levado adiante por Prestes Maia em sua administração (1938-1945) demarcou o futuro da expansão modernizadora da capital paulista. Desafogou o centro da cidade através da abertura de amplas avenidas, o primeiro anel perimetral e as avenidas de irradiação e definiu a expansão rumo à zona sul da cidade, agora ligada ao centro não apenas pelo bonde, mas pelo sistema " $y$ " de avenidas. Pode-se dizer que a implantação dos conjuntos residenciais dos institutos de previdência na capital paulista acompanhou a expansão urbana traçada pelo Plano de Avenidas.

Independente das formas tomadas pelas intervenções entre 1940 e 1960 no Rio de Janeiro ou em São Paulo, é certo que a estruturação das periferias foi carreada por uma ação pública. Ao longo das malhas ferroviárias que foram sendo implantadas desde o último quartel do século XIX, estabeleceu-se a ocupação suburbana, por meio da intensificação do papel estratégico desses canais de comunicação. Os planos para eletrificação das estradas de ferro acompanharam a ocupação impulsionada pela presença dos investimentos públicos. Mesmo considerando-se o aspecto por vezes 
fragmentário dessa ação, é possível localizar, por exemplo, ao longo do eixo da Central do Brasil que liga São Paulo ao Rio de Janeiro, a reestruturação do território, sobretudo, daqueles próximos às áreas com vocação industrial, com investimentos em habitação para abrigar os trabalhadores industriais. Desta forma, vê-se nas principais cidades brasileiras, a circunscrição, ao longo da ferrovia, das estratégias de organização da cidade industrial (em que pese todas as contradições políticas que impregnaram o processo de urbanização desses territórios).

\section{A redemocratização e a política urbana brasileira}

Poucos trabalhos tem se dedicado a analisar a produção habitacional promovida pelo Estado e a estruturação da cidade industrial brasileira em uma perspectiva que não àquela que comprove a ineficácia dos programas ou a forma de reprodução de um sistema excludente e segregador.

Pelo sucesso e pertinência do legado interpretativo desta vertente historiográfica, que demonstrou no problema habitacional as características do capitalismo periférico enfatizando a insuficiência das ações do Estado, a falta de regulação do mercado de terras e o compromisso com as classes dominantes, poucos trabalhos tem considerado a tarefa do Estado Varguista na modernização de uma sociedade rural e na transformação de um modelo político eivado pelo clientelismo.

Muito contribui para essa dissociação o engajamento dos analistas desta vertente do problema habitacional com o processo de redemocratização brasileiro. As análises produzidas durante a ditadura militar no Brasil (1964-1985) e mesmo àquelas que se seguiram, tenderam ao julgamento anacrônico, na medida em que identificaram a Era Vargas (1930-1954), o Estado Novo (1937-1945) e o paternalismo caudilhista do ditador, com o presente histórico pós 1964.

A história das políticas habitacionais brasileiras se constrói através do conflito entre a ampliação do atendimento do "Estado do bem estar social" e a dificuldade de sua reprodução na periferia do capitalismo. A impossibilidade de generalizar o serviço de assistência social, incluindo uma política habitacional massiva e garantindo a expansão "democrática" da sociedade urbana no Brasil constituiu-se em um fecundo debate durante o período de industrialização brasileira.

Nesse sentido, expondo os casos do Rio de Janeiro e de São Paulo analisamos as várias ações e inações no setor habitacional e o sentido que adquirem na experiência histórica da "cidade industrial brasileira", com as suas formas de moradia dos trabalhadores urbanos, e sua relação com a estruturação e produção da cidade. 
O desenvolvimento econômico industrial dirigido pelo Estado tem início no Brasil com a revolução de 1930 e impulsiona definitivamente o processo de urbanização. É fato que tal processo perdura durante a ditadura militar implantada por golpe de estado em março de 1964, entretanto os compromissos do Estado com o progresso social e o tipo de desenvolvimento promovido neste período transformamse na medida em que se aprofundam as conexões entre sistema nacional e o internacional. (Fernandes, [1974] 2006).

A super oferta de mão de obra concentrada nas cidades, fundamental para a industrialização brasileira no Período Varguista constituiu-se, ao mesmo tempo, em um elemento estratégico para o desenvolvimento econômico industrial, como reserva abundante de força de trabalho, e em um potencial político de apoio à instalação da nova ordem social, base da política trabalhista sobre a qual se funda o ciclo do desenvolvimentismo brasileiro. Por outro lado o agravamento das condições de vida e de alojamento nas grandes cidades colocava em risco a própria organização social que condicionava a escalada da urbanização da população brasileira, que entre 1940 e 1970 alcançou cerca de 40 milhões de pessoas. (Instituto Brasileiro de Geografia e Estatística 2011). Vislumbrando as relações dialéticas e atentando para tal complexidade é que se busca novas formas de interpretar a produção da habitação e da cidade no período histórico varguista.

\section{Referências}

A VEZ dos subúrbios. Boletim O Construtor. Rio de Janeiro, 03 de Dezembro, 1943. ABREU, Maurício. (2006). Evolução Urbana do Rio de Janeiro. Rio de Janeiro: Prefeitura da Cidade do Rio de Janeiro, Secretaria Municipal de Urbanismo - SMU, Instituto Municipal de Urbanismo Pereira Passo - IPP.

ALMEIDA, R. (1952). "Carta ao Vice-Presidente da Comissão Nacional de Bem-Estar Social encaminhando sugestões da Subcomissão de Habitação e Favelas para solucionar o problema de habitação popular". Rio de Janeiro: CPDOC Arquivo: Getúlio Vargas. Classificação: GV c 1952.12.23. Data:23/12/1953. ARAÚJO FILHO, J. R. (1958). "A população paulistana". In AZEVEDO, A (org.) A

Cidade de São Paulo, estudos de geografia urbana. São Paulo: Companhia Editora Nacional, vol. III, p. 180.

AZEVEDO, A (Org.) (1958). A Cidade de São Paulo, estudos de geografia urbana. Vols I a IV. São Paulo: Companhia Editora Nacional. 
BARBOSA, A. F (Coord.)(2012). "Rômulo Almeida e as bases econômicas e institucionais para o desenvolvimento da nação". Relatório de pesquisa do Programa Cátedras IPEA/CAPES para o Desenvolvimento.

BONDUKI, N. (1998). Origens da habitação social no Brasil: arquitetura moderna, Lei do Inquilinato e difusão da casa própria. São Paulo: FAPESP, Estação Liberdade.

BOTAS, N. C. A. (2011). Entre o progresso técnico e a ordem política: arquitetura e urbanismo na ação habitacional do IAPI. São Paulo: Tese de Doutorado, FAU-USP.

BRITTO, A.; GUIMARÃES, A. P.; SERRAN, J. R. (1985). Habitação popular: inventário da ação governamental. São Paulo: FINEP, Projeto.

CHATEUBRIAND, Assis. (1939). "Contra o urbanismo artificial". Revista do IAPC. Rio de Janeiro: IAPC; jan. p. 33.

COHN, A. (1981). Previdência social e processo político no Brasil. São Paulo: Editora Moderna.

CONNIFF, Michael L. (2006). Política urbana no Brasil: a ascensão do populismo 1995-1945. Rio de Janeiro: Relume Dumará.

ENGELS, F. [1887] (1974). El problema de la vivienda y las grandes ciudades. Barcelona: Gustavo Gili.

FERNANDES, F. [1974] (2006). A Revolução Burguesa no Brasil: Ensaio de Interpretação Sociológica. 3a. Edição. Rio de Janeiro: Editora Guanabara.

FREITAS Fo., Almir Pita de. (2002). "O desenvolvimento industrial no rio de janeiro na primeira metade do século xx: transformações urbanas e a indústria da construção civil". Anais do X Encontro Regional de História - ANPUH/RJ. História e Biografias. Rio de Janeiro: UERJ. (Também disponível em: http://www.rj.anpuh.org).

FREITAS, M. L. e KOURY, A. P.(2010). "Habitação Social, cidade jardim e standard. A busca por um ideário pitoresco e racional construtivo". In: XI Seminário de História da Cidade e do Urbanismo, Vitória.

INAUGURAÇÃo de casas proletárias. Boletim O Construtor. Rio de Janeiro, 21 de Agosto, 1942.

KOURY, A P. (2005). Proposições para a produção material da arquitetura contemporânea no Brasil. São Paulo: Tese de doutorado, FAU - USP.

MANOEL, S. K. (2004). Fundação da Casa Popular: projeto frustrado de construção de uma política habitacional no Brasil. São Carlos: Dissertação de mestrado. EESC - USP. 
MATOS, Dirceu Lino de. (1958). "O parque industrial paulistano". In AZEVEDO, Aroldo (Org.). A cidade de São Paulo: Estudos de Geografia Urbana. São Paulo: São Paulo Editora S.A. Vol III. pp. 41-42.

OLIVEIRA, F. [1972] (2003). Crítica à razão dualista: o ornitorrinco. São Paulo: Boitempo editorial.

OS SUBÚRBIOS e as obras públicas. Boletim O Construtor. Rio de Janeiro, 26 de Novembro, 1943.

PETRONE, Pasquale. "São Paulo no Século XX". In AZEVEDO, Aroldo. A cidade de São Paulo: Estudos de Geografia Urbana. São Paulo: São Paulo Editora S.A, 1958. Vol III, p. 149.

REIS FILHO, N. G.(1968). Contribuição ao estudo da evolução urbana do Brasil (1500 a 1720). São Paulo: Pioneira.

RESENDE, Vera F. (2002). "Planos e regulação urbanística: a dimensão narrativa das intervenções na cidade do Rio de Janeiro". In: OLIVEIRA, Lucia Lippi. CIDADE: história e desafios (Org.). Rio de Janeiro: Ed. Fundação Getulio Vargas.

RIBEIRO, L. C. de Q.; PECHMAN, R. M. O. (1985). O que é questão da moradia. São Paulo: Nova Cultural, Brasiliense.

ROCHA, Antônio. (1958). "Os subúrbios de S. Paulo e suas funções". In AZEVEDO, Aroldo. (Org.). A cidade de São Paulo: Estudos de Geografia Urbana. São Paulo: São Paulo Editora S.A. Vol IV, p. 7.

SANTOS, W. G. (2006). O Ex-Leviatã Brasileiro. Rio de Janeiro: Civilização Brasileira.

SILVA, Zélia Lopes da. (1983). A Face Oculta da Reprodução. Um estudo sobre os trabalhadores rurais em São Paulo: 1930/34. Dissertação de Mestrado. Campinas: IFCH/UNICAMP.

SINGER, P. (1968) Desenvolvimento econômico e evolução urbana. São Paulo: Editora Nacional.

IBGE. Situação demográfica, estado da população do Brasil na data do recenseamento geral de 1940. Distribuição, segundo os municípios, IBGE Estatísticas do Século XX. (disponível em www.ibge.com.br. Acesso em 18/04/2013).

UNITED NATION (1969). Growth of the world's urban and rural population. Department of Economic and Social Affairs. Population Studies, No. 44. New York: United Nations. 